\title{
A biblioteca escolar como agente potencializador do processo ensino-aprendizagem
}

\author{
The school library as a potentiating agent of the teaching-learning process
}

\author{
Barbara Lipinski \\ Mestranda em Ciência da Informação pela Universidade Estadual de Londrina - UEL, Brasil. \\ https://orcid.org/0000-0003-2861-1359 \\ E-mail: babilipinski@ hotmail.com \\ Poliana Fragatti Cristovam \\ Mestre em Ciência da Informação pela Universidade Estadual de Londrina - UEL, Brasil. \\ https://orcid.org/0000-0002-2935-1301 \\ E-mail: poli.bibcal@gmail.com
}

\section{Resumo}

\begin{abstract}
A biblioteca escolar é de suma importância no contexto educacional, embora nem sempre, ao longo de sua história, tenha sido reconhecida como tal. Considerando que ela desempenha, hoje, um papel que vai muito além de um espaço para promoção de leitura, este artigo objetiva compreender a importância da biblioteca escolar como um instrumento no processo de ensino-aprendizagem, a fim de identificar a relevância do apoio da coordenação pedagógica e dos professores para esse processo, bem como empregar atividades facilitadoras que possam colaborar para tornar essa teoria uma possível realidade. Para tanto, realizou-se uma pesquisa de natureza qualititativa, revisão bibliográfica e relato de experiência em uma instituição particular do ensino básico, pertencente a uma rede educacional, localizada no norte do estado do Paraná. Os resultados apontaram que o trabalho interdisciplinar é imprescindível para uma melhor prestação de serviços para a comunidade escolar, bem como a participação ativa e cooperativa do bibliotecário, da coordenação e do corpo docente faz deles os principais agentes potencializadores do processo de ensinoaprendizagem, quebrando paradigmas e criando um conceito diferente de biblioteca escolar, tanto para o corpo discente quanto para o docente.
\end{abstract}

Palavras-chave: Biblioteca escolar. Ensino-aprendizagem. Biblioteca - Instrumento pedagógico. Bibliotecário.

\begin{abstract}
The school library is of paramount importance in the educational context, although it has not always been recognized as such throughout its history. Considering that it plays, today, a role that goes far beyond a space for reading promotion, this article aims to understand the importance of the school library as an instrument in the teaching-learning process, in order to identify the relevance of the coordination support pedagogical and teachers for this process, as well as employ facilitating activities that can collaborate to make this theory a possible reality. To this end, a qualitative research, bibliographic review and experience report was carried out in a private institution of basic education, belonging to an educational network, located in the north of the state of Paraná. The results showed that interdisciplinary work is essential for better service delivery to the school community, as well as the active and cooperative participation of the librarian, the coordination and the teaching staff, making them the main potentializing agents of the teaching-learning process, breaking paradigms and creating a different concept of school library, both for the student body and for the teacher.
\end{abstract}

Keywords: School library. Teaching and learning. Library - Educational tool. Librarian.

Bibl. Esc. em R., Ribeirão Preto, v. 7, n. 2, p. 61-81, 2021.

DOI: 10.11606/issn.2238-5894.berev.2021.178594 
A biblioteca escolar como agente potencializador do processo ensino-aprendizagem

\section{Introdução}

O estereótipo de biblioteca como guarda-livros precisa mudar. Segundo Roca (2012), não é questão de inventar uma nova biblioteca escolar, uma vez que essa anseia por uma renovação pedagógica devido aos novos recursos tecnológicos, o que implica mudanças na biblioteca já que ela deverá realizar uma função de apoio em todo esse processo de mudança.

A biblioteca escolar, nesse contexto, está em um crescente. Antes era vista apenas como espaço estático e pouco utilizado; porém, na contemporaneidade, este conceito tem mudado, tendo ela como tarefa principal acompanhar as mudanças no processo de ensino e aprendizagem, tornando-se parte dele com um intuito de apresentar, assim, um novo conceito de atividades propostas e do profissional bibliotecário que a coordena.

$\mathrm{Na}$ literatura, encontram-se conceitos que destacam a importância pedagógica da biblioteca, como visto por Lourenço Filho (1946, p. 3-4) de que

\footnotetext{
ensino e biblioteca são instrumentos complementares [...], ensino e biblioteca não se excluem, completam-se. Uma escola sem biblioteca é um instrumento imperfeito. A biblioteca sem ensino, ou seja, sem a alternativa de estimular, coordenar e organizar a leitura, será por seu lado, instrumento vago e incerto (LOURENÇO FILHO, 1946, p. 34).
}

Com base em tal conceito, pode-se destacar a biblioteca escolar como mais do que um recurso. Já que o que justifica sua existência "não é a biblioteca em si como estrutura organizacional estável [...], mas seu uso como recurso educacional facilitador do desenvolvimento de processos de ensino-aprendizagem" (ROCA, 2012, p. 24), ou seja, que vem para apoiar o desenvolvimento do projeto curricular da escola. No entanto, seu êxito em atrair leitores depende do acervo bibliográfico e do profissional que nela atua (CALDIN, 2005). Surge, então, a necessidade de uma reciclagem profissional do bibliotecário que trabalha em biblioteca escolar, a fim de se adequar a tais realidades.

Segundo Lanzi, Vidotti e Ferneda (2013), tornou-se fundamental a mudança da imagem do bibliotecário, sobretudo do bibliotecário escolar. Falar a mesma linguagem e compartilhar dos mesmos interesses é praticamente indispensável, uma vez que "o novo perfil bibliotecário, apresenta um profissional engajado, dinâmico, antenado as novas tecnologias, que trabalha em equipe, e que consegue mediar os anseios dos usuários" (LANZI; VIDOTTI; FERNEDA, 2013, p. 
34). Dessa maneira, a biblioteca escolar precisa ser reconhecida como recurso essencial no processo de ensino-aprendizagem, inserida neste contexto educacional, mediante as percepções dos professores e dos coordenadores pedagógicos, pois entende-se que tais profissionais precisam estar em sincronia para o êxito das atividades realizadas.

Assim, para compreender a importância da biblioteca escolar como um instrumento no processo de ensino-aprendizagem, é preciso enfatizar e conceituar o perfil do bibliotecário nesse contexto, com o propósito de identificar a importância do apoio da coordenação pedagógica e dos professores para esse processo e empregar atividades facilitadoras que possam colaborar para tornar essa teoria uma possível realidade. Com esse propósito, realizou-se uma pesquisa em uma instituição particular do ensino básico, pertencente a uma rede educacional, localizada no norte do estado do Paraná.

\section{Procedimentos metodológicos}

Baseada nas afirmações de Gil (2008), a natureza caracterizou-se como aplicada, por proporcionar novos conhecimentos; a abordagem do problema foi qualitativa, devido à prática interpretativa de investigação; os procedimentos técnicos foram de revisão bibliográfica, por utilizar materiais já publicados. Optou-se por trazer um relato descritivo de experiência, baseandose nas atividades executadas, dada a relevância da contribuição para a área de atuação, descrevendo as vivências profissionais, contribuindo para futuras discussões, troca ou proposição de ideias.

Dada a informação, o cenário de estudo foi um colégio particular do norte do estado do Paraná, que atende da educação infantil ao ensino médio, tendo aproximadamente 600 alunos. O colégio tem alguns anos de funcionamento, esse passou por uma reforma significativa e percebeu que não apenas a estrutura, mas serviços oferecidos de qualidade eram importantes, então investiuse na contratação de uma bibliotecária especialista na área educacional. Nesse sentido, o relato aqui apresentado, descreve as práticas executadas após o processo de observação e de adaptação da profissional, pois é importante ressaltar que ações são realizadas apenas após o conhecimento da comunidade; sendo assim este processo ocorreu durante dois anos de atuação, entre 2017 e 2018, e contou com o apoio administrativo e pedagógico da unidade educacional. 
A biblioteca escolar como agente potencializador do processo ensino-aprendizagem

\section{Biblioteca escolar: breve histórico e missão}

É difícil precisar o surgimento da biblioteca escolar. O primeiro registro no Ocidente, nos Estados Unidos, é de 1740, quando Benjamin Franklin recomendou a biblioteca escolar como fundamental para uma academia ideal. Entretanto, foi a partir de 1835 que os norte-americanos começaram a refletir sobre o uso de recursos públicos para a criação e para a manutenção de bibliotecas escolares. Em 1876, Melvil Dewey criou a American Library Association (ALA), ação que impulsionou ainda mais o desenvolvimento das bibliotecas escolares. A partir do século XX, essas bibliotecas cresceram e se desenvolveram como setores fundamentais nas escolas (AMERICAN..., 2011?).

No Brasil, a discussão sobre a necessidade de biblioteca escolar surgiu apenas em 1849, quando o político Vicente P. da Mota alertou a Assembleia Legislativa de São Paulo com a instrução de implantação de uma biblioteca na província local (VÁLIO, 1990).

É importante ressaltar que a biblioteca escolar, como entendida hoje, no Brasil, foi fundada com as Escolas Normais. A primeira biblioteca escolar data de 1880, na Escola Normal Caetano de Campos, em São Paulo e, em 1894, foi inaugurada a Biblioteca do Ginásio do Estado da Capital. As bibliotecas escolares continuaram surgindo, mas a partir de 1930 é que elas começaram a se desenvolver e ser criadas nos ginásios estaduais (INL, 1994 apud VÁLIO, 1990).

Todavia uma valorização maior da biblioteca escolar ocorreu após 1920, com a Escola Nova. Estudiosos como Dewey, Freinet, Montessori e outros contribuíram para essa inserção e para a valorização. Eles defendiam a utilização da biblioteca para o desenvolvimento intelectual do

aluno por meio da leitura e da pesquisa, da utilização de livros, da utilização do espaço para crianças com baixa capacidade de aprendizagem, para a socialização e para o avanço de projetos como parte de um processo de criação e comunicação (CREMADES GARCÍA; JIMÉNEZ FERNÁNDEZ, 2015 apud FIORAVANTE, 2018).

Anos se passaram até que, em 24 de maio de 2010, foi sancionada a Lei federal n ${ }^{\circ} 12.244$, que dispõe sobre a universalização das bibliotecas escolares, a qual afirma que instituições de ensino público ou privado devem contar com bibliotecas, com um mínimo de materiais bibliográficos e um bibliotecário, estabelecendo um prazo de dez anos para o seu cumprimento (BRASIL, 2010). Supõe-se que a Lei, com suas preposições, auxiliou as instituições de ensino Bibl. Esc. em R., Ribeirão Preto, v. 7, n. 2, p. 61-81, 2021. 
básico há terem um parâmetro para a consolidação da biblioteca em suas unidades educacionais, assim se torna primordial definir sua missão.

A FEDERAÇÃO... (2015, p. 19) descreve que a missão da biblioteca escolar

fornece informação e ideias fundamentais para sermos bem sucedidos na sociedade atual, baseada na informação e no conhecimento. A biblioteca escolar desenvolve nos estudantes competentes para a aprendizagem ao longo da vida e desenvolve a imaginação, permitindo-lhes tornarem-se cidadãos responsáveis (FEDERAÇÃO..., 2015, p. 19).

Côrte e Bandeira (2011) destacam que a biblioteca escolar tem o papel de incentivar a leitura reflexiva, pois mediante ela os alunos terão outra concepção do texto, repleto de significados, ajudando no ensino.

Ensino e biblioteca não se excluem, completam-se. Uma escola sem biblioteca é instrumento imperfeito. A biblioteca sem ensino, ou seja, sem a tentativa de estimular, coordenar e organizar a leitura, será, por seu lado, instrumento vago e incerto. Começa a compreensão destas ideias, felizmente, a vigorar entre nós. Certas bibliotecas escolares se modernizam, e passam a funcionar de forma menos ineficiente. Outras ensaiam orientar os leitores, sugerir-lhes trabalhos, proporcionar-lhes melhores recursos de organização (LOURENÇO FILHO, 1946, p. 4).

Santos (1973, p. 148) pontua que "a biblioteca deve ser o lugar onde os alunos se sirvam diariamente para complementar os conhecimentos adquiridos em classe". Campello (2012) dialoga sobre, assinalando que pesquisas recentes relacionadas à educação mostram que bibliotecas escolares têm hoje um papel que vai muito além de um espaço de promoção de leitura, elas são, principalmente, espaços de aprendizagem. Côrte e Bandeira (2011) acordam ressaltando que a biblioteca escolar é mais que um recurso para serviços biblioteconômicos, já que seu uso se justifica como recurso educacional facilitador do desenvolvimento de processos de ensino-aprendizagem.

A biblioteca estará em conjunção com a nova pedagogia da leitura, transformando-se num centro de documentação, incluindo, além dos livros, o material audiovisual utilizado por professores e alunos. Esta é a biblioteca que se integraria no ensino pregado pela nova pedagogia, que viria a personalizar a vida da escola (SANTOS, 1973, p. 175).

No diálogo dos autores citados, apresenta-se de forma significativa a palavra "aprendizagem", pontuando a biblioteca como um instrumento importante nesse processo. Surge, então, a necessidade de conceituar e falar sobre o ensino, já que o ensino gera a aprendizagem.

$\mathrm{Na}$ literatura, as palavras "ensino" e "aprendizagem" são apresentadas separadas, primeiramente, para depois serem vinculadas, formando um conceito muito utilizado no meio 
educacional. Para entender melhor tal conceito, é importante conhecer os paradigmas que as envolvem.

\section{Biblioteca escolar: um instrumento para o processo ensino-aprendizagem}

O termo "ensino" é apresentado por muitos autores na literatura, por conseguinte é preciso focar apenas nos que o abordam no âmbito educacional, em que se inicia a rotina acadêmica.

Gregory (1996, p. 1) descreve que "o ensino tem suas leis naturais tão fixas quanto as leis que governam o crescimento dos organismos". Para o autor, "ensinar, no seu sentido mais simples, é transmitir conhecimento" (GREGORY, 1996, p. 2), entretanto, a epistemologia da palavra é apresentada como "a fonte da aprendizagem" (BECKER, 2012, p. 33). De acordo com Piaget (1974, p. 33), "a educação deve favorecer a compreensão" e seu papel se reduz a uma instrução, enriquecer ou alimentar as faculdades, acumular conhecimentos (PIAGET, 1974).

Unindo os termos ensinar e aprender, Freire (1997, p. 143) destaca que "ensinar e aprender têm a ver com o esforço metodicamente crítico [...] desvelar a compreensão de algo e com o empenho igualmente crítico do aluno ir entrando como sujeito em aprendizagem". Todavia, segundo Libâneo (1994, p. 90) "a relação entre ensino e aprendizagem não é mecânica, não é uma simples transmissão [...] que ensina para um aluno que aprende".

Levando em consideração o meio em que está, o ensino é realizado de forma prática. Quando se apresentam conceitos sobre aprendizagem, a literatura pontua sobre a importância de que a aprendizagem seja significativa, em que o aluno associe o conteúdo ensinado com o meio em que está inserido.

Para que se possa haver aprendizagem é necessário que haja todo um processo de assimilação onde o aluno com orientação [...] passa a compreender, refletir e aplicar os conhecimentos que foram obtidos, assim a aprendizagem é observada com a colocação em prática por parte do aluno dos conhecimentos que foram transmitidos durante uma aula ou atividade (LIBÂNEO, 1994, p. 149).

Fernández (1998, p. 33, tradução nossa) disserta que a reflexão sobre o estado atual do processo ensino-aprendizagem "permite identificar um movimento de ideias de diferentes correntes teóricas sobre a profundidade do binômio ensino e aprendizagem”. Kubo e Botomé (2001) destacam que o processo de ensino-aprendizagem é um nome para um complexo sistema 
de interação comportamental entre educador e educando. Acredita-se que o ensino e a aprendizagem não estão presentes somente em sala de aula, pois perpassa por diferentes atores, assim se considera presente na biblioteca, pois é um recurso inserido na escola para auxiliar na construção do conhecimento contribuindo, assim, para a educação.

Em consonância a esta afirmação, a Base Nacional Comum Curricular (BNCC) estabelece para a educação as chamadas competências, determinando as habilidades que os alunos deverão desenvolver durante seu período na escola, da educação infantil ao ensino médio. Definida como práticas cognitivas e socioemocionais, as atitudes e os valores promoverão demandas complexas da vida cotidiana, para o desenvolvimento do exercício da cidadania e do mundo do trabalho, reconhecendo que a "educação deve afirmar valores e estimular ações que contribuam para a transformação da sociedade (...)" (BRASIL, 2017, p. 8).

Resumidamente o Instituto Nacional de Estudos e Pesquisas Educacionais Anísio Teixeira (INEP) descreve que as competências são classificadas em dez categorias, sendo elas: conhecimento; pensamento científico, crítico e criativo; repertório cultural; comunicação; cultura digital; trabalho e projeto de vida; argumentação; autoconhecimento e autocuidado; empatia e cooperação; responsabilidade e cidadania. A BNCC ainda apresenta um tópico "O que posso encontrar na biblioteca", estabelecendo que se poderão encontrar diversos recursos que apoiem a implementação da BNCC, ou seja, evidenciando o possível diálogo entre biblioteca e escola.

Côrte e Bandeira (2011, p. 8) asseveram que a atuação da biblioteca na unidade educacional favorece o enriquecimento cultural, pois sua atuação reflete as diretrizes da escola. Não sendo um setor isolado, o bibliotecário não conseguirá transformar a biblioteca em um instrumento facilitador no processo de ensino-aprendizagem sem apoio pedagógico. As autoras afirmam que é a biblioteca escolar que deve atuar como órgão auxiliar e complementar da escola, facilitando aos alunos o livre acesso aos livros, ao mundo do saber, às descobertas, e ao prazer na descoberta da leitura.

A biblioteca escolar é um espaço de construção do conhecimento ao fazer uso do acervo e tudo o mais que é disponibilizado para a aprendizagem, não sendo mera reprodutora de serviços biblioteconômicos, mas um ambiente de ensino-aprendizagem. Roca (2012, p. 24) afirma que “o que justifica a existência da biblioteca escolar [...] é seu uso como recurso educacional facilitador do desenvolvimento de processos de ensino-aprendizagem e práticas de leitura". 
Sendo seu papel e missão intimamente atrelado a escola, é a biblioteca escolar que faz a ponte entre conhecimento de mundo e a comunidade em que está inserida, Côrte (2011, p. 3) indaga que a biblioteca escolar tem o papel de incentivar a leitura reflexiva, pois por meio dela os alunos terão outra concepção do texto e de mundo, que repleto de significados ajudaram no ensino.

Nessa perspectiva, alguns atores ganham destaque neste processo, dentre eles, a figura do bibliotecário, que para Fleck e Pereira (2007, p. 287 apud SOUZA, 2011, p. 20) acreditam que "a presença do bibliotecário nas escolas é importante, pois esse profissional auxilia no processo de ensino e aprendizagem". Nesse sentido, torna-se importante dialogar sobre tais atores.

\section{Agentes potencializadores do processo ensino-aprendizagem: bibliotecário, professor e coordenador pedagógico}

Todo o processo transformador do ensino-aprendizagem precisa ser realizado e potencializado por agentes humanos. Lanzi, Vidotti e Ferneda (2013, p. 74) enfatizam que “o bibliotecário é o principal responsável pela mobilização da biblioteca escolar”. Os autores ainda pontuam que

para que a biblioteca se torne ativa, [...] precisa ser dinâmico, aberto ao novo, criativo, capaz de promover situações diversas que favoreçam o desenvolvimento informacional dos educandos, estruturar o ambiente, de modo que se torne agradável, atrativo e lúdico e os usuários sintam-se inseridos nele (LANZI; VIDOTTI; FERNEDA, 2013, p. 74).

Um dos pontos é a participação do bibliotecário nas atividades pedagógicas da escola. "O bibliotecário deve participar da vida escolar de seus usuários, participando do desenvolvimento do programa educativo do professor" (CÔRREA, 2002, p. 5). O autor ainda defende a ideia que "o bibliotecário precisa participar ativamente de todos os acontecimentos que circulam o ambiente escolar" (CÔRREA, 2002, p. 5). Entretanto, é necessário lembrar que, na maioria das instituições do ensino básico, este profissional não é incluído no processo educativo, é apenas lembrado no momento da leitura e das pesquisas básicas.

Bezerra (2008) pontua cinco características negativas de exclusão do bibliotecário como potencializador do ensino-aprendizagem: 
Barbara Lipinski e Poliana Fragatti Cristovam

não participa diretamente do processo pedagógico; não participa do planejamento escolar; não existe comunicação com o corpo docente em relação ao conteúdo desenvolvido em sala de aula; restringe-se ao atendimento do pedido do aluno, fazendo por ele as ações de busca e seleção de informações; não organiza oficinas, com intuito de ensinar os procedimentos adequados para a elaboração de um trabalho escolar (BEZERRA, 2008, p. 8).

Com as novas demandas informacionais, "a pressão de fatores econômicos, tecnológicos e sociais, os profissionais na informação têm sido levados a se adaptar a uma nova realidade" (LANZI; VIDOTTI; FERNEDA, 2013, p. 78), destarte “tornou-se indispensável a mudança da imagem do bibliotecário, sobretudo a do bibliotecário escolar, para que ele mantenha um bom relacionamento com seu público, fale a linguagem e compartilhe os seus interesses (LANZI; VIDOTTI; FERNEDA, 2013, p. 79).

Conforme apregoa Corrêa et al (2002), o bibliotecário é um educador. Os autores assinalam que para entender melhor este conceito é importante refletir sobre o que é educar. Educar, "[...] corresponde à tarefa de transmitir a cada nova geração os usos e costumes de cada comunidade, além de tentar transmitir o conjunto de valores que prezamos" (GIKOVATE, 2001 apud CORRÊA et al. 2002, p. 5). Além disso, os autores pontuam (2002, p. 4) as três principais funções da biblioteca: educativa, cultural e social e recreativa, considerando o profissional que nela trabalha, o bibliotecário, que ele deve seguir esta linha.

Na práxis pedagógica, o educador, é aquele que, tendo adquirido cultura necessária para o desempenho de suas atividades, dá direção ao ensino e aprendizagem. Ele assume o papel de mediador entre a cultura elaborada, acumulada e em processo de acumulação pela humanidade e o educando (LUCKESI, 1994, p. 115).

O educador necessita de algumas qualidades:

ter a compreensão da realidade com a qual trabalha, com a sociedade na qual atua; Comprometimento político, compreendendo a sociedade que vive [...]; competência no campo teórico de conhecimento em que atua, para desempenhar com adequação as atividades; sempre se atualizar buscar novas atualizações da área; competência técnicoprofissional, ou seja, deter recursos técnicos e habilidades de comunicação que facilitem a apropriação do que se comunica. [..] necessita possuir habilidades na utilização e aplicação de procedimentos de ensino (LUCKESI, 1994, p. 115).

Nessa concepção, pontuando os perfis do educador e do bibliotecário, é perceptível a concordância entre os dois:

1. Conhecimento e atendimento às necessidades individuais dos alunos no processo de ensino-aprendizagem, bem como nos seus interesses de leitura;

2. Atualização a respeito das novas atividades, métodos e materiais educativos;

Bibl. Esc. em R., Ribeirão Preto, v. 7, n. 2, p. 61-81, 2021. 
A biblioteca escolar como agente potencializador do processo ensino-aprendizagem

3. Exercício de papel de mediador entre informação/conhecimento e seu usuário, possuindo para tal, competência teórica e aptidões profissionais advindas de formação específicas do caso;

4. Motivação e estímulo à pesquisa, despertando no aluno o gosto pela leitura. (CORRÊA et al., 2002, p. 6).

Destarte, fica clara a defesa do conceito de o bibliotecário também ser um educador. No entanto, é importante o apoio do professor, pois não adianta o bibliotecário ser empenhado e colaborativo, com intensão de promover a biblioteca escolar, se o professor não utilizar os serviços e os recursos da biblioteca como possível complemento dos conteúdos ensinados em sala de aula.

Silva (1989) afirma que se não há uma participação ativa e constante entre esses, dificilmente haverá dinamização da biblioteca escolar na prática. Dessa forma, evidencia a grande responsabilidade na mudança de atitude do bibliotecário dentro do contexto escolar. Silva (1989) ainda assevera que se não há integração entre o profissional da biblioteca e o professor, cria-se um conflito que refletirá na função educativa da biblioteca.

Alguns dos possíveis motivos pelos quais os professores se afastam da integração com o bibliotecário, segundo Bezerra (2008, p. 8),

se a escola mantém uma biblioteca, nem sempre o professor acompanha os alunos nesse espaço; quando os encaminha, conduz um número muito grande de alunos e ao mesmo tempo, para utilizaram o serviço da biblioteca; o professor não define adequadamente o tema e o que deverá ser coletado; não indica referências bibliográficas; quando informa [...], restringe-se somente a uma obra (BEZZERA, 2008, p. 8).

O trabalho deve ser desenvolvido em conjunto, em que bibliotecário, professor e acrescenta-se a figura do coordenador, necessitam trabalhar de forma integrada. Lanzi, Vidotti e Ferneda (2013, p. 79) pontuam que "o bibliotecário precisa trabalhar em sintonia com a coordenação pedagógica e professores [...] para que essa mudança aconteça".

Para tal deveria transformar o bibliotecário comum num verdadeiro especialista da pedagogia da pesquisa e da leitura. Um bibliotecário que se relacionasse, como tal, com os diretores, os professores e os demais responsáveis pelos serviços educativos, para que pudesse delinear com segurança os métodos que permitissem à biblioteca atender aos objetivos da pedagogia moderna (SANTOS, 1973, p. 175).

O bibliotecário deve “[...] ser um profissional engajado, dinâmico, antenado às novas linguagens da Web, colaborativo, que sabe trabalhar em equipe, mediar os anseios dos usuários, empreendedor" (LANZI; VIDOTTI; FERNEDA, 2013, p. 79, grifo nosso).

Bibl. Esc. em R., Ribeirão Preto, v. 7, n. 2, p. 61-81, 2021. 
Entende-se que trabalhar na biblioteca escolar de forma isolada é prejudicial, levando em consideração que "a biblioteca representa um trabalho de dinamização e participação no sistema escolar" (ROCA, 2012, p. 25). Ademais, a biblioteca precisa se desenvolver junto à equipe pedagógica e aos professores para que suas atividades se potencializem; esta parceria profissional fará a biblioteca ter suas atividades potencializadas. A imagem do coordenador é importante, pois ele trabalhará estimulando o professor a desenvolver atividades em parceria com a biblioteca e apoiará as atividades por ela desenvolvidas. Lima e Santos (2007) indicam que dentre as funções do coordenador pedagógico, estão: acompanhar o professor em suas atividades de planejamento e estimular os professores a desenvolverem com entusiasmo atividades de promoção educativas.

Na Idade Média, já dizia o poeta John Donne: “nenhum homem é uma ilha”. Em qualquer área de atuação profissional, trabalhar de forma isolada pode acarretar muitos pontos negativos e perca de potencial de trabalho. Economias (2016) pontua quatro razões para não trabalhar sozinho: duas cabeças pensam melhor que uma, o isolamento tem efeitos negativos para o trabalhador, as ameaças são invisíveis e a criatividade sai para dar espaço à repetição.

A formação de equipes interdisciplinares é de suma importância para a eficácia na construção e no desenvolvimento de atividades. De acordo com Piaget (1973, p. 143, tradução nossa), a interdisciplinaridade é "o nível em que a interação entre várias disciplinas ou setores heterogêneos de uma mesma ciência conduz a interações reais, a uma certa reciprocidade no intercâmbio levando a um enriquecimento mútuo". Observa-se que o conhecimento de cada membro da equipe pode contribuir para a excelência no trabalho, gerando melhores resultados, tudo isso com o objetivo de aperfeiçoar o trabalho e os serviços prestados, nesse caso, aos alunos. O conhecimento compartilhado do bibliotecário, do professor e do coordenador pedagógico contribui muito para a eficácia do serviço.

Se o processo de ensino-aprendizagem for considerado prático e, necessariamente, houver uma relação entre o indivíduo que está transmitindo o conhecimento e aquele que recebe tal conhecimento, sendo importante para fazer relação com o meio cultural e social do aluno, pode-se entender, então, que a participação ativa e cooperativa de coordenação, professores e bibliotecários é de extrema relevância, tornando esses os principais agentes potencializadores para que a biblioteca escolar se torne um instrumento de ensino-aprendizagem, desenvolvendo, assim, atividades para tal transformação. 
A biblioteca escolar como agente potencializador do processo ensino-aprendizagem

\section{Ações que auxiliam na transformação da biblioteca escolar em um instrumento de ensino-aprendizagem}

Considerando as funções principais da biblioteca escolar: educativa, cultural, social e recreativa (CORRÊA et al., 2002), e as atividades propostas realizadas em conjunto com professores e coordenadores pedagógicos, serão apresentadas, nesta seção, ações que podem tornar a biblioteca escolar um instrumento no processo de ensino-aprendizagem. Para tal, tem-se como base a biblioteca de uma instituição privada do ensino básico, localizada no norte do estado do Paraná, que passou por este processo e hoje é vista, de fato, como um instrumento de apoio ao processo de ensino-aprendizado por professores, alunos e coordenação, tudo isso em consequência da integração entre esses.

Antes de projetar qualquer atividade, primeiramente é importante disponibilizar aos alunos um ambiente agradável, com arquitetura moderna, "que fale a linguagem dos jovens e das crianças. Um ambiente alegre e colorido" (LANZI; VIDOTTI; FERNEDA, 2013, p. 89). Assim, o primeiro passo da instituição de ensino foi reestruturar a biblioteca escolar, transformando-a em um ambiente semelhante às características apresentadas pelos autores.

Vive-se em um mundo digital, no qual crianças e adolescentes vivem conectados na web, desse modo foi considerada a instalação de televisores smartphones, divididas pelos ambientes da biblioteca - espaço para educação infantil e ensino fundamental I e um outro ambiente para alunos do ensino fundamental II. Lanzi, Vidotti e Ferneda (2013, p. 82) enfatizam que "a biblioteca precisa estar estruturada para receber ou ir aonde estão seus usuários, seja numa sala de aula ou na Web". Nesse viés, além da instalação da internet Wifi, um laboratório de informática móvel, com uma quantia significativa de tabletes, foi deixado à disposição dos usuários para pesquisas ou aulas no ambiente digital.

Após a estrutura, é importante ter uma boa equipe, que fale a linguagem da comunidade que irá atender e esteja preparada para elaboração de atividades educativas, culturais e sociais. Essa equipe é composta por bibliotecários e auxiliares. "Bibliotecas não existem apenas por causa de livros e informação. As bibliotecas também servem para facilitar as pessoas a participarem, interagirem e criarem. A biblioteca fornece os meios para que isso aconteça" (PARTRIDGE; LEE; MUNRO, 2010, p. 316 apud LANZI; VIDOTTI; FERNEDA, 2013, p. 80). 
O próximo passo é disponibilizar um acervo atualizado e atraente aos gostos literários dos alunos. Nessa etapa do processo, instalou-se um software gerenciador com um banco de dados contendo livros digitais, a fim de agradar ao público que gosta de livros físicos e ao público que gosta de livros digitais. "O bibliotecário é o profissional que tem contato com os leitores, conhece seus gostos, interesses e necessidades. Está perfeitamente gabaritado para atuar como crítico na seleção do acervo" (CALDIN, 2005, p. 2). Ademais, nessa instituição, foi elaborada a Política de Desenvolvimento de Coleções, com destaque para a seleção de materiais, a qual é feita por uma comissão, na qual bibliotecário e professor indicam títulos para compor o acervo da biblioteca uma vez que se entende que a parceria e o trabalho em conjunto devam ocorrer em todos os aspectos.

Para a seleção de literatura infantil, Caldin (2001) lista alguns aliados: concursos literários nacionais, feiras, catálogos dos autores disponibilizados pelas editoras etc.; outro adepto, também, é o material didático utilizado, pois sabendo os conteúdos trabalhados em sala de aula a escolha dos paradidáticos que complementarão o acervo fica mais fácil. Contudo, quando o assunto é literatura infantojuvenil, a seleção fica mais complexa, pois agradar este público nem sempre é uma tarefa fácil.

A literatura de massa tem sido, cada vez mais, a iniciação dos adolescentes à leitura. Tem
levado dezenas, centenas de adolescentes às livrarias em busca do livro que tanto querem
ler; tem sido assunto de suas conversas e tem feito com que desejem ler outros livros,
sejam eles continuação da saga, indicação de amigos ou os que deram origem a um filme
ou séries de televisão (LOURENÇO, 2010, p. 375).

Partindo deste pressuposto, a iniciativa foi começar o contato com os usuários nessa linha. Assistir às séries que eles assistiam trouxe o conhecimento sobre os atores e sobre o que estes liam e indicavam em suas redes sociais. Após esse laço afetivo, era só contar "a novidade" e indicar o que os personagens "teens" estavam citando em suas hashtags. O investimento foi de tempo e dinheiro. Nesse ponto, pode-se perceber a importância de estabelecer ações de marketing.

Equipe preparada, acervo organizado e atualizado; no entanto, antes de qualquer desenvolvimento de atividade, é importante ter um planejamento anual, assim as ações se norteiam conforme a necessidade da escola, do corpo docente e discente. Soares (2016) afirma que o planejamento ajuda a alcançar os objetivos estabelecidos. No caso das bibliotecas escolares, este planejamento é relevante estar acordado conforme datas comemorativas e projetos integradores da escola.

Bibl. Esc. em R., Ribeirão Preto, v. 7, n. 2, p. 61-81, 2021. 
A biblioteca escolar como agente potencializador do processo ensino-aprendizagem

Para pontuar as ações desenvolvidas e que corroboraram para alcançar o objetivo inicial apresentado, será feito o uso de alíneas, conforme seguem abaixo:

a) Projeto base para leitura: por meio de um projeto base, foram estabelecidos objetivos e ações para todos os seguimentos da escola, da educação infantil ao ensino médio. Após objetivos traçados, foi criado uma logomarca para o projeto.

b) Sacolinha da leitura: com o logotipo criado pela equipe de marketing, contratou-se uma empresa que produziu uma bag porta-livros, confeccionada com tecido de garrafa PET. O objetivo foi trabalhar com as crianças da educação infantil ao $5^{\circ}$ ano sobre a importância de preservar os livros, já que a bag serve para a criança levar e trazer o livro. Cada uma é identificada com série, turma e nome. Além de trabalhar a conscientização com o planeta, também foi uma ação de marketing para instituição de ensino, já que a logomarca fica estampada na bag.

c) Dia de biblioteca: para a educação infantil ao $5^{\circ}$ ano, estabeleceu-se no calendário semanal uma hora/aula para estar na biblioteca. Nesse momento, as turmas têm a possibilidade de emprestar um livro para levar para casa e ler com a família.

d) Hora do conto: no dia da biblioteca acontece a hora do conto, semanalmente. Mediante de temas pré-definidos, sejam de conteúdos de sala de aula ou do dia a dia, todas são trabalhadas de forma lúdica para incentivar a leitura.

e) Aulas na biblioteca: aulas de português e literatura foram acrescentadas ao planejamento dos professores do ensino fundamental II para que os alunos possam associar a biblioteca como um lugar de aprendizagem.

f) Livro-prova: foram escolhidos e estabelecidos títulos de livros paradidáticos para servir de base para conteúdos de provas durante o bimestre para os alunos do ensino fundamental II e médio.

g) Bibliocine: quando o livro paradidático trabalhado pelo professor tinha possibilidade de filme, os dois formatos eram apresentados aos alunos. O filme é passado com pipoca para ajudar e a animar os adolescentes para o mundo das letras. 
Barbara Lipinski e Poliana Fragatti Cristovam

h) Biblioteca na sala de aula: uma biblioteca itinerante é montada nas salas dos alunos da educação infantil ao $5^{\circ}$ ano. Em cada término de atividades e provas, os alunos podem ler, não ficando ociosos.

i) Ações culturais: há teatros com temas pré-definidos, feiras de livros em parceria com professores para a atividade ser interdisciplinar e exposições das atividades criadas nas aulas de artes.

j) Ações com a comunidade: em datas de escola de pais, reuniões, entregas de boletim etc., são feitas, na biblioteca, palestras com especialistas em assuntos que ajudem no dia a dia dos pais. Temas como autoconfiança, relacionamento entre pais e filhos, importância do incentivo aos estudos, orçamento familiar, são alguns dos abordados.

k) Datas comemorativas: todo calendário escolar tem feriados nacionais e datas que são destacados nas escolas. Nessas datas, procura-se fazer algo diferente e que agregue sentido ao dia a dia do aluno. Um exemplo foi no Dia Mundial da Saúde Bucal, convidou-se um dentista para ensinar às crianças como melhorar a escovação os dentes e depois todos ganharam uma escova dental e foram praticar o aprendido.

1) Semana de mediação da informação: é uma semana literária, mas voltada em mediar alguma informação que a comunidade está precisando. Um exemplo foi o tema "Comportamento digital e as Fake News". Vários jornalistas foram convidados para trabalhar com cada seguimento escolar, o assunto de forma especializada, para que todos entendessem.

m) Chá literário: alguns títulos são escolhidos para serem trabalhados em formato de chá com as turmas do ensino médio. Um ambiente é montado ao ar livre, o chá é servido durante o tempo do programa, e no decorrer dele são lidos trechos do livro, discutidos assuntos dele, levantadas curiosidades etc.

n) Produção literária / noite do autógrafo: durante as aulas de Redação são escritos textos em gêneros poéticos ou contos. Após a escrita, cada turma do ensino fundamental II, do $6^{\circ}$ ao $9^{\circ}$ ano, escolhe uma capa que a identifique e lança um livro em uma noite de autógrafos organizada pela escola. 
A biblioteca escolar como agente potencializador do processo ensino-aprendizagem

o) Autor na escola: dependendo do livro trabalhado, um autor é convidado a cada semestre para estar na escola. Assim, o aluno tem a possiblidade de ter contato com a pessoa que pensou na história e tem a possiblidade de fazer perguntas. Esta iniciativa proporciona um interesse maior entre os alunos para ler e produzir textos.

p) Premiações de incentivo à leitura: é a premiação das turmas que mais leem durante o ano. Uma medalha, um troféu, ou algo diferenciado, faz com que o aluno se sinta estimulado a ler mais. Uma das alternativas adotadas são os vale-compras em livrarias, ele é um sucesso em aceitação.

\section{Considerações finais}

A pesquisa objetivou compreender a importância da biblioteca escolar como instrumento no processo de ensino-aprendizagem, enfatizando e conceituando o perfil do bibliotecário nesse contexto. Os objetivos da pesquisa pautaram-se em identificar a importância do apoio da coordenação pedagógica e dos professores para esse processo e assinalar algumas atividades facilitadoras realizadas em uma instituição privada do ensino básico no norte do estado do Paraná que corroboraram para tornar esta teoria uma possível realidade.

Observou-se que a biblioteca escolar demorou muito tempo para chegar ao formato como hoje é conhecida. Após anos de discussão sobre a importância de ter um espaço como tal nas unidades escolares do país, vieram leis que colaboraram e nortearam a implantação desse. Por meio da pesquisa, pode-se averiguar que muitos autores pontuam a importância da biblioteca no processo de ensino-aprendizagem. Ela pode ser um instrumento e não apenas um mero reprodutor de serviços biblioteconômicos, além disso, representa um trabalho de dinamização e participação no sistema escolar.

É perceptível que, com o passar dos anos, a sociedade mudou bem como o perfil da escola mudou com as novas necessidades informacionais dos alunos; dessa forma, houve a necessidade de uma mudança, como um todo, no setor educacional. A biblioteca que antes era vista como um espaço de silêncio e cores frias passou a ser um espaço colorido e dinâmico. 
O estudo destacou que o bibliotecário é um agente potencializador do processo de ensinoaprendizagem, porém ele pode deixar de ser quando não participa diretamente do processo pedagógico e do planejamento escolar, não dialoga com o corpo docente, torna o aluno dependente de suas explicações na biblioteca, não organiza atividades complementares para apoiar as ações da sala de aula etc. Foi perceptível a importância de uma mudança: deixar de ser técnico e passar a ser dinâmico e cooperativo.

A biblioteca escolar abrange três principais funções: educativa, cultural e social e recreativa, dessa maneira o bibliotecário é conceituado como um educador, pois ele tem compreensão da realidade em que trabalha e da sociedade em que atua, conhece bem a teoria com vistas a desenvolver atividades práticas e sempre se atualiza buscando aprimorar seus conhecimentos. Com o perfil definido, algo em destaque no presente trabalho é a importância em desenvolver ações por meio de parcerias: bibliotecário, coordenação pedagógica e professores. Neste conjunto, a biblioteca passa a ter suas atividades potencializadas, pois com a fuga dos alunos da biblioteca ações precisam ser realizadas para ela deixar de ser vista como um depósito.

Foi possível conhecer ações realizadas em uma biblioteca de uma instituição privada do ensino básico, localizada no norte do estado do Paraná, sendo possível destacar como conseguiu quebrar paradigmas. Mediante um planejamento anual construído com base no calendário escolar, foi possível destacar possíveis atividades para tornar a biblioteca um instrumento no processo de ensino-aprendizagem. Com investimento adequado, foi possível ter uma nova arquitetura que atende ao novo perfil da biblioteca escolar, passando a ser colorida, dinâmica, com espaço subdivididos e aparelhos eletrônicos. Outro destaque é que a biblioteca deixou de ser um espaço entre quatro paredes, passando a ir até a sala de aula por intermédio da biblioteca itinerante.

Também foi possível averiguar ações culturais de auxílio à comunidade que foram realizadas para que essa entendesse que a biblioteca é um instrumento que atende às necessidades informacionais tanto nos aspectos acadêmicos quanto culturais e sociais no espaço que está inserida. Projetos de leitura, hora do conto, bibliocine foram algumas das ações destacadas no presente trabalho.

De modo geral, verificou-se que a biblioteca pode ser um espaço de destaque na escola. Com uma equipe preparada, um ambiente adequado, força de vontade e criatividade é possível transformar a biblioteca em um instrumento valioso no processo de ensino-aprendizagem, todavia, 
A biblioteca escolar como agente potencializador do processo ensino-aprendizagem

ressalta-se que, na maioria das vezes, a iniciativa será do bibliotecário. Acomodar-se sempre será mais fácil, pois instituir cultura, prazer pela leitura e o estudo em um país que não tem esses assuntos como prioridade, sempre será uma tarefa difícil, porém não impossível. Este cenário perpassa por diferentes atores e a discussão torna-se relevante para a área da biblioteconomia, pois dialogar sobre prática é importantíssimo para a troca de experiência, sendo a literatura rica em conhecimento teórico, somente por meio de relatos tornará visível as práticas existentes que corroboram com o fazer do profissional e com pesquisas futuras.

\section{Referências}

AMERICAN LIBRARY ASSOCIATION (ALA). First school library? [S. l.: s. $n$.], 2011 ? Disponível em: http://www.ala.org/tools/first-school-library. Acesso em: 22 nov. 2020.

BECKER, F. Educação e construção do conhecimento. 2. ed. Porto Alegre: Penso, 2012.

BEZERRA, M. A. da C. O papel da biblioteca escolar: importância do setor no contexto educacional. CRB-8 Digital, São Paulo, v. 1, n. 2, p. 4-10, out. 2008. Disponível em: https://brapci.inf.br/index.php/res/v/9177. Acesso em: 27 nov. 2020.

BRASIL. Ministério da Educação. Base Nacional Comum Curricular: educação é a base. 2017. Disponível em:

http://portal.mec.gov.br/index.php?option=com docman\&view=download\&alias=79611-anexotexto-bncc-aprovado-em-15-12-17-pdf\&category_slug=dezembro-2017-pdf\&Itemid=30192. Acesso em: 27 nov. 2020.

BRASIL. Lei n⿳ 12.244 de maio de 2010. Dispõe sobre a universalização das bibliotecas nas instituições de ensino do País. Brasília, DF: Presidência da República, 2010. Disponível em: http://www.planalto.gov.br/ccivil_03/_ato2007-2010/2010/lei/112244.htm. Acesso em: 27 nov. 2020.

CALDIN, C. F. O bibliotecário, a criança e a literatura infantil: algumas ponderações. Revista ACB: Biblioteconomia em Santa Catarina, Florianópolis, v. 6, n. 1, p. 111-128, 2001. Disponível em: https://revista.acbsc.org.br/racb/article/view/362/429. Acesso em: 27 nov. 2020.

CALDIN, C. F. Reflexões acerca do papel do bibliotecário de biblioteca escolar. Revista ACB: Biblioteconomia em Santa Catarina, Florianópolis, v. 10, n. 2, p. 163-168, jan./dez., 2005. Disponível em: https://revista.acbsc.org.br/racb/article/view/431/549. Acesso em: 27 nov. 2020.

CAMPELLO, B. Biblioteca escolar: conhecimentos que sustentam a prática. São Paulo: Autêntica, 2012. 
Barbara Lipinski e Poliana Fragatti Cristovam

CAMPELLO, B. Perspectivas de letramento informacional no Brasil: práticas educativas de bibliotecário em escolas de ensino básico. Encontros Bibli: Revista Eletrônica de Biblioteconomia, Florianópolis, v. 15, n. 29, p. 184-208, 2010. Disponível em: https://periodicos.ufsc.br/index.php/eb/article/view/1518-2924.2010v15n29p184/19549. Acesso em: 3 jul. 2020.

CORRÊA, E. C. D. et al. Bibliotecário escolar: um educador? Revista ACB, Florianópolis, v. 7 , n. 1. 2002. Disponível em: https://revista.acbsc.org.br/racb/article/view/379/458. Acesso em: 05 jul. 2020.

CÔRTE, A. R. e; BANDEIRA, S. P. Biblioteca escolar. Brasília: Briquet de Lemos, 2011.

ECONOMIAS. 5 fortes razões para não trabalhar sozinho. Matosinhos, 27 out. 2016.

Disponível em: https://www.economias.pt/razoes-nao-trabalhar-sozinho/. Acesso em: 27 nov. 2020.

FERNÁNDEZ. F. A. Fundamentos teóricos del processo de optimización, nexos entre optimización y calidad de la enseñanza. In: INSTITUTO PEDAGÓGICO LATINOAMERICANO Y CARIBEÑO. Didáctica y optimización del proceso de enseñanzaaprendizaje. La Habana, Cuba: [s. n.], 1998. Disponível em: https://pt.calameo.com/read/0002331685a3073245309. Acesso em: 27 nov. 2020.

FIORAVANTE, E. O sentido de biblioteca escolar expresso por alunos de escolas públicas de Santa Catarina: entre livros, descobertas, refúgio e abandono. 2018. 568 f. Tese (Doutorado em Ciência da informação) - Universidade Federal de Santa Catarina, Centro de Ciências da Educação, Florianópolis, 2018. Disponível em: https://repositorio.ufsc.br/handle/123456789/190697. Acesso em: 27 nov. 2020.

FREIRE, P. Pedagogia da autonomia: saberes necessários à prática educativa. 2. ed. Rio de Janeiro: Paz e Terra, 1997.

GIL, A. C. Métodos e técnicas de pesquisa social. 6. ed. São Paulo: Atlas, 2008.

GREGORY, J. M. As sete leis do ensino. São Paulo: Casa Publicadora Batista, 1996.

FEDERAÇÃO INTERNACIONAL DE ASSOCIAÇÕES E INSTITUIÇÕES BIBLIOTECÁRIAS. Diretrizes da IFLA para a biblioteca escolar. 2. ed. rev. 2015. Tradução: Rede de Bibliotecas Escolares (Portugal). Disponível em: https://www.ifla.org/files/assets/school-libraries-resource-centers/publications/ifla-school-libraryguidelines-pt.pdf. Acesso em: 22 nov. 2020.

KUBO, O. M.; BOTOMÉ, S. P. Ensino-aprendizagem: uma interação entre dois processos comportamentais. Interação em Psicologia, Curitiba, v. 5, 2001. Disponível em: https://revistas.ufpr.br/psicologia/article/view/3321. Acesso em: 27 nov. 2020. 
A biblioteca escolar como agente potencializador do processo ensino-aprendizagem

LANZI, L. A. C.; VIDOTTI, S. A. B. G.; FERNEDA, E. A biblioteca escolar e a geração nativos digitais: construindo relações. São Paulo: Cultura Acadêmica, 2013. Disponível em: https://repositorio.unesp.br/handle/11449/109286. Acesso em: 27 nov. 2020.

LIBÂANEO, J. C. Os métodos de ensino. São Paulo: Cortez, 1994.

LIMA, P. G.; SANTOS, M. S. O coordenador pedagógico na educação básica: desafios e perspectivas. Educere at Educare: Revista de Educação, Cascavel, v. 2, n. 4, p. 77-90, jul./dez. 2007. Disponível em: http://e-revista.unioeste.br/index.php/educereeteducare/article/view/1656. Acesso em: 27 nov. 2020.

LOURENÇO, D. S. Adolescentes leem sim: a circulação da literatura nas escolas. In: COLÓQUIO DA PÓS-GRADUAÇÃO DE LETRAS, UNESP, 2., 2010, Assis. Anais [...] Assis: UNESP, 2010. p. 372-383. Disponível em:

https://www.scielo.br/scielo.php?script=sci_arttext\&pid=S0104-40602015000300191. Acesso em: 27 nov. 2020.

LOURENÇO FILHO, M. O ensino e a biblioteca. Rio de Janeiro: Imprensa Nacional, 1946.

LUCKESI, C. C. Filosofia da educação. São Paulo: Cortez, 1994.

PIAGET, J. Para onde vai a educação? Rio de Janeiro: José Olympio, 1974.

PIAGET, J. L'epistemologie des relations interdisciplinaires. In: APOSTEL, L.; BERGER, G.; BRIGGS, A.; MICHAUD, G. L'interdisciplinarité: problemes d'enseignement et de recherche dans les universites. Paris: Organization de Coperation et Developpement Économiques, 1973.

ROCA, G. D. Biblioteca escolar hoje: recurso estratégico para a escola. Porto Alegre: Penso, 2012.

SANTOS, I. R. A biblioteca escolar e a atual pedagogia brasileira. Revista de Biblioteconomia de Brasília, Brasília, v. 1, n. 2, p. 145-149, jul./dez., 1973. Disponível em:

https://periodicos.unb.br/index.php/rbbsb/article/view/23793. Acesso em: 27 nov. 2020.

SILVA, E. T. da. Biblioteca escolar: quem cuida? In: GARCIA, E. G. (coord.). Biblioteca escolar: estrutura e funcionamento. São Paulo: Loyola, 1989.

SOUZA, A. G. O perfil do bibliotecário escolar em Florianópolis. 2011. 41 f. Monografia (Graduação em Biblioteconomia) - Universidade Federal de Santa Catarina, Centro de Ciências da Educação, Florianópolis, 2011. Disponível em:

https://repositorio.ufsc.br/bitstream/handle/123456789/121175/301515.pdf?sequence=1. Acesso em: 27 nov. 2020.

SOARES, D. Qual a importância do planejamento? Por que planejar? João Pessoa, 11 dez. 2016. Disponível em: http://www.administradores.com.br/artigos/empreendedorismo/qual-aimportancia-do-planejamento-por-que-planejar/100730/. Acesso em: 27 nov. 2020. 
VÁLIO, E. B. M. Biblioteca escolar: uma visão histórica. Transinformação, Campinas, v. 2, n. 1, jan./abr., 1990. Disponível em: http://periodicos.puccampinas.edu.br/seer/index.php/transinfo/article/view/1670. Acesso em: 27 nov. 2020.

Artigo submetido em: 30 nov. 2020

Artigo aceito em: 04 maio 2021

Bibl. Esc. em R., Ribeirão Preto, v. 7, n. 2, p. 61-81, 2021. 